\title{
Corregir la técnica
}

\author{
Correct the technique
}

\section{Correção da técnica}

Fecha de entrega: 22 de julio de 2013

Fecha de evaluación: 15 de noviembre de 2013

Fecha de aprobación: 20 de diciembre de 2013

Antonio González

\section{Resumen}

El autor presenta una reflexión en torno al concepto de technê según la tradición filosófica antigua hasta el periodo contemporáneo. Su propósito es exponer una nueva visión de la técnica, entendida como un surgir dirigido que nos permite considerar su vinculo con la naturaleza creativa del hombre y la ciencia.

Palabras clave: técnica, ciencia aplicada, surgir dirigido, creatividad humana.

\section{Abstract}

The author presents a reflection on the concept of technê according to ancient philosophical tradition up to contemporary period. The purpose is to present a new vision of the technique, understood as a

* Filósofo y teólogo español vinculado con la Fundación Xavier Zubiri, pensador al cual el propio González ha dedicado importantes estudios. Igualmente sus investigaciones tratan asuntos de la fenomenología, esto desde la praxis social y la teologia social, en la que desarrolla una crítica hacia la teología de la liberación. Correo electrónico: antoniogonzalez@zubiri.net 
directed appearance that allows us to consider its connection with the creative nature of men and science.

Keywords: Technique, applied science, directed appearance, human creativity.

\section{Resumo}

O autor apresenta uma reflexão sobre o conceito de technê segundo a tradição filosófica antiga ao período contemporâneo. Sua finalidade é apresentar uma nova visão da arte, entendida como um surgir dirigido que nos permite considerar o vínculo com a natureza criativa de homem e ciência.

Palavras-chave: Técnica, ciência aplicada, surgir dirigido, a criatividade humana. 
Aristóteles, en el primer libro de la Metafísica, tiende a considerar la técnica o arte (technê) como un tipo de saber, a medio camino entre la experiencia y la ciencia, aunque más cercano a esta última. Este planteamiento, aunque no agota el enfoque aristotélico de la técnica, destaca el aspecto intelectivo de la ciencia, algo que culmina en la idea moderna de la "tecnología” como ciencia aplicada. Desde un punto de vista opuesto, se puede considerar la técnica como un hacer adaptado al entorno, y, en este sentido, como una prolongación de la evolución, tal como sucede en la filosofía de Bergson. Otras aproximaciones filosóficas a la técnica la entienden como una transformación de la circunstancia exigida por el carácter mismo de la vida humana (Ortega), como un destino del Ereignis (Heidegger) o como invención de realidades y poder sobre realidades (Zubiri). Ciertamente, en los siglos pasados la técnica ha sido considerada en ocasiones de manera fuertemente crítica, recordando su función en un sistema económico opresivo (Marx), el dominio que la técnica ejerce sobre el ser humano (como el Gestell de Heidegger) y su función ideológica en la sociedad industrializada (Habermas). Sin embargo, la filosofía ha prestado clásicamente poca atención a algo que hoy nos resulta especialmente preocupante en la técnica: sus efectos destructivos sobre el entorno. Nos hemos dado cuenta de que los efectos colaterales de la técnica, lejos de ser fácilmente controlados, amenazan aquello mismo que la técnica viene posibilitando desde la noche de los tiempos: nuestra propia supervivencia.

Curiosamente, los mitos y las religiones ya contenían alusiones a los efectos negativos de la técnica. En la versión platónica del mito de Prometeo, la sabiduría técnica (y no solo el fuego) aparece como una posesión divina, sustraída por este famoso titán a los dioses y entregada a la humanidad para su supervivencia y su bienestar (euporía). Ciertamente, el relato de Platón no menciona más efecto negativo de la técnica que el castigo que Prometeo sufre por su robo. Pero otras versiones del mito relacionan la sustracción del fuego con el castigo que Zeus infringe a los hombres y no solo al titán. Ese castigo consiste precisamente en la creación de la primera mujer, Pandora, $y$, con ella, la introducción en el mundo de la famosa caja de plagas con la que se castiga a la humanidad. Los relatos bíblicos reflexionan sobre el origen de la técnica de una manera distinta. En el relato sobre el zigurat de Babel, la técnica no aparece como una posesión divina, sino como una creación humana. Y una creación que no es primeramente característica del pueblo que trasmite el relato, sino más bien de los imperios hostiles de su entorno. La técnica, consistente en la capacidad de fabricar ladrillos y utilizar brea para unirlos, no desciende del cielo a la tierra, sino que sirve 
a la pretensión imperial de alzarse de la tierra hacia el cielo, construyendo grandes y vistosos ingenios técnicos para lograr de este modo la admiración de la humanidad. El efecto que consigue es, sin embargo, el opuesto: al final del relato la humanidad queda dividida y el paisaje distorsionado por las ruinas inacabadas del vano intento humano de alcanzar la estatura de los dioses.

¿Son esos relatos simples reliquias de una desconfianza primitiva en la técnica, destinada a ser superada por la ilustración?; ¿o se toca con ellos alguna dimensión constitutiva de la técnica a la que la filosofía no ha prestado suficiente atención? No es posible responder a estas preguntas sin enfrentarnos filosóficamente de nuevo a la cuestión de qué es la técnica. Para esta tarea nos encontramos con una clásica dificultad, y es que la técnica parece incluir de forma maravillosa tanto el saber como el hacer. Como ya decía Aristóteles, la técnica es un saber que puede ser enseñado. Pero no basta con saber para ser un técnico: también es necesario el momento y el hacer. La dificultad en la conceptuación de la técnica parece tener que ver con la posible unilateralidad en el papel que se adjudique a cada uno de estos elementos. Por una parte, sería injusto entender la técnica como una mera ciencia aplicada, ignorando la contribución específica que la actividad técnica ha prestado al desarrollo de las ciencias desde sus orígenes. Por otra parte, sería igualmente ingenuo entender la técnica como la alternativa evolutiva del homo faber a la especialización de los órganos animales. La técnica, más que una mera adaptación al entorno natural, incluye el propósito consciente de transformación de ese entorno para adaptarlo a los proyectos humanos; no solo para sobrevivir, sino para vivir mejor; no solo para estar en el mundo, sino también, como decía Ortega, para "bien-estar en el mundo". La unidad de saber y de hacer en la técnica no se consigue tratando de reducir uno de estos dos elementos al otro, sino que más bien nos exige pensar qué es lo que efectivamente une en la técnica a estos dos momentos constitutivos suyos.

Muchas de las filosofías contemporáneas de la técnica han señalado una raíz común para ambos momentos en instancias tales como la vida (Ortega), la realidad (Zubiri) o el Ereignis (Heidegger). No es este el momento de ponderar las ventajas y los límites de estos planteamientos. Aquí queremos llamar la atención sobre algo normalmente desatendido por ellos y que, sin embargo, es esencial para nuestra cuestión: tanto el hacer como el saber son actos, y pudiera ser que la consideración misma de la índole propia de todo acto nos sirviera no solo para entender la raíz de la vinculación entre hacer y saber en el caso de la técnica, sino también para incluir una consideración de 
sus efectos más indeseados. Pero, entonces, ¿qué entendemos por acto? No parece correcto definir los actos a partir de aquellas presuntas sustancias o sujetos que los producen, porque esto nos traslada desde los actos mismos hacia condiciones de posibilidad que normalmente no resultan accesibles al análisis. Es preferible, por ello, entender los actos desde lo que en ellos acontece. Y lo que acontece en los actos, en todo tipo de actos, es el surgir de las cosas. Esto puede decirse de todo tipo de actos: la imaginación es el surgir de las cosas imaginadas, la sensación es el surgir de la cosa sentida, el pensamiento es el surgir de las cosas pensadas, la percepción es el surgir de las cosas percibidas, el cálculo matemático es el surgir de las cosas calculadas, etc. Los mismos movimientos corporales consisten en un surgir, tanto de las cosas que al movernos surgen o resurgen en nuevas formas, como del propio cuerpo cuyo surgir se modifica en el propio movimiento.

Es importante llamar la atención sobre un aspecto esencial de este surgir que constituye los actos. El surgir no es un mero aparecer (phaínesthai) fantasmagórico, en el que las cosas quedarían como meras apariencias. El surgir es, etimológicamente, un sub-rego. Las cosas, al surgir, rigen, de tal manera que el mismo acto de surgir queda bajo (sub) aquello que surge. Este regir de lo que surge no es sino su alteridad radical en el mismo surgir: las cosas surgen como radicalmente otras respecto al surgir mismo. Las cosas no surgen como remitiendo al surgir o a la persona ante la que surgen. Las cosas surgen remitiendo solamente a sí mismas. Las cosas no surgen como otras para nuestros actos, sino como tan radicalmente otras que les trae sin cuidado su propio surgir ante nosotros. No se trata de ninguna explicación realista sobre el conocimiento, sino simplemente de un análisis de lo que sucede en el mismo surgir, y sin pretender trascenderlo. El surgir es siempre un surgir de las cosas y nunca el de los propios actos. Los actos permanecen invisibles, como aquello tan inmediato a nosotros mismos que no es accesible en ningún otro acto. La rememoración de un acto pasado no hace que el surgir mismo surja ante nosotros: solamente surge, en forma modificada, lo que anteriormente surgió. Los actos no surgen en otros actos, sino que ellos son el surgir mismo de las cosas. Solamente surgen las cosas. Estas cosas, al remitir a sí mismas, rigen a los actos, que quedan remitidos a ellas. Precisamente, por ello, el surgir de las cosas contiene siempre incoado el lanzamiento hacia la realidad profunda de esas cosas, hacia aquello de las cosas que posibilita su mismo surgir.

Los griegos solamente entrevieron el surgir, pero no lo llegaron a conceptuar sistemáticamente como un estricto surgir (hypárkhein), sino más bien como un nacer 
o brotar (physis). Evidentemente, el modelo del brotar y del nacer parece muy apto para pensar el surgir de las cosas naturales, pero no el de las cosas artificiales. Los productos de la técnica no se caracterizan por brotar o nacer. Sin embargo, las cosas artificiales, al igual que las cosas naturales, surgen ante nosotros y se imponen sobre nosotros. Ciertamente, la atención a los productos no basta para cualificar la técnica. De hecho, la técnica produce cosas naturales, no solo en la época de los productos sintéticos y de las clonaciones, sino desde los orígenes mismos de la agricultura. Pero el cuestionamiento de la distinción clásica entre lo artificial y lo natural no se realiza cumplidamente atendiendo solamente a la común realidad de lo artificial y lo natural, sino destacando la índole común de todo acto, caracterizado por el surgir de las cosas, más allá del hecho de que ante nosotros surjan cosas naturales o artificiales. Ello no obsta para que, dentro del ámbito del surgir, común a todo acto, podamos preguntarnos por la índole propia de los actos que integran la técnica. Pues bien, la técnica no se caracteriza por el hecho de que sus productos finales sean naturales o artificiales. Aquello que caracteriza a la técnica es que ella es un surgir dirigido. Ya se trate de clonar una oveja o simplemente de seleccionar unos granos, ya se trate de construir una nave espacial o simplemente de permitir la recuperación de un entorno natural, aquello que caracteriza a la técnica en cuanto tal es que, en ella, el surgir está dirigido.

Examinemos esto más detenidamente. El di-rigir es un regir de nuevo: hay de nuevo, un momento de dominancia. Pero este regir ya no es el de la alteridad radical de las cosas que surgen. En la técnica nos encontramos, además, con un regir que se orienta hacia el surgir mismo. La técnica es un surgir dirigido: el surgir mismo está ahora regido, porque se le impone una "di-rección”. Esta dirección es algo más que el sentido que pueden tener algunas de las cosas que surgen. Es una dirección que pretende regir el acontecer mismo del surgir, imponiéndole un logos. Ya se seleccionen los granos para la siembra, se fabrique una herramienta, se perfeccione una estirpe animal o se construya un navío, en todos los casos tenemos un surgir dirigido según una intención humana. A la técnica le corresponde esencialmente esta intencionalidad que dirige el surgir. Por eso, no se puede dar cuenta cabal de la técnica humana atendiendo solamente a las sensaciones y a los movimientos, como hacía Zubiri. Ciertamente, las sensaciones y los movimientos son actos, o constelaciones de actos, que intervienen en la técnica. Pero lo que caracteriza a la técnica como tal no es solo la presencia de estos actos, sino la dirección sobre el surgir. La técnica es un surgir dirigido. La presencia de este momento intencional implica, por tanto, que 
la técnica no consta solamente de acciones, sino también de lo que podríamos llamar actuaciones. No solo eso. La dirección del surgir implica necesariamente la indagación racional sobre las estructuras que posibilitan el surgir de las cosas. La técnica, como ya observaba Aristóteles, se pregunta el porqué (to dióti), y en ese aspecto constituye una actividad constitutivamente racional (meta lógou aletho-us), estructuralmente vinculada siempre a formas más o menos elaboradas de ciencia.

La descripción de la técnica como un surgir dirigido nos permite entender la creatividad propia de la ciencia. Evidentemente no se trata de creación ex nihilo, sino una creatividad que parte del surgir mismo. La técnica se monta sobre aspectos previos del surgir, sea uno natural (physis) o uno dirigido previamente, que ahora son reorientados. El invento técnico no es algo que aparece de la nada, sino algo que se instala y se encuentra (invenire) sobre un surgir previo, que ahora adquiere una nueva dirección. Esta dirección no apunta solamente a las cosas que surgen, a los productos antiguos y nuevos de la actividad técnica. Tampoco se limita a los instrumentos que se fabrican y que sirven para producir cosas u otros instrumentos. El surgir dirigido incluye un regir de los mismos procesos productivos, que se formalizan y se regularizan. Se trate de un proceso artesanal o de una moderna cadena fabril, el regir técnico domina también a la producción y no solo al producto. No solo eso. La dirección técnica incluye también a las personas que intervienen en el proceso de la producción. La técnica, como surgir dirigido, es dirección sobre cosas y personas. Ya Aristóteles decía que si las lanzaderas tejiesen por sí mismas, y el arco tocase solo la lira, no se necesitarían esclavos. Cualquier consideración crítica sobre las estructuras de dominación asociadas con las diversas formas de la técnica humana a lo largo de la historia ha de partir de la inexorable dirección que caracteriza al surgir técnico como dirigido.

Sería una ingenuidad pensar, sin embargo, que la técnica tiene simplemente unos sujetos humanos que la dirigen, a través de la dirección de los procesos y personas implicados. La persona no es un sujeto por debajo de sus actos, sino la carne misma del surgir. Por eso, el regir de lo que surge afecta a todas las personas envueltas en los procesos técnicos y no solo a los que son dirigidos por otros. Aunque no todos sean transformados en meros "recursos humanos", todos son regidos por lo que va surgiendo en la actividad técnica. Los instrumentos, las máquinas, los procesos adquieren el carácter de un sistema que rige a las personas y las somete a determinaciones que escapan a su control voluntario. Las reflexiones de Heidegger sobre la técnica como 
un "montaje" (Gestell) tienen aquí su lugar propio. El ser humano, como aprendiz de brujo, queda dominado y abarcado por la técnica que él mismo ha creado. Pero no se trata de algo exclusivo del capitalismo contemporáneo, sino de procesos que incipientemente caracterizan a todo surgir y, por fuerza, al que está dirigido, sea cual sea la índole concreta de cada civilización. Lo que surge, por su alteridad radical respecto al surgir, tiene siempre el carácter de un poder que, en distintos modos, se impone también sobre quienes pretenden dirigir el surgir. La técnica, como surgir dirigido, no solo engloba los actos del surgir, sino también aquello que surge, en el surgir mismo, como radicalmente otro que el surgir. Todo producto de la técnica, y no solo los modernos sistemas del mundo industrializado, es algo que rige el surgir mismo, y adquiere una dominancia sobre él. Por eso mismo, a la técnica le pertenecen esencialmente sus resultados. Y estos resultados técnicos son los que eventualmente pueden llegar a utilizarse como legitimación de la técnica misma, en el sentido en el que Habermas habla de la técnica como ideología.

Ahora podemos ver lo incompleto de la distinción aristotélica entre acción (praxis) y producción (poiésis), cuando afirma que la primera tiene su fin en sí misma (como tocar la flauta por el placer de tocarla) y la segunda tiene su fin fuera de sí misma (construir una casa). Desde esta perspectiva, Aristóteles no duda en adscribir la técnica al ámbito de la producción y no al de la acción. Al hacerlo, olvida que al surgir (hypárkhein) pertenece también lo que surge, y lo que surge ejerce un poder (arkhetn) sobre el surgir, hasta el punto de someterlo bajo (hypo-) su dominio. Dicho en otros términos: la técnica, una vez constituida en su alteridad radical respecto al propio surgir, puede llegar a determinar los propios fines de este. El artesano queda atado a su taller, el agricultor a sus aperos, el obrero a su máquina, el empresario a su capital, y todos los occidentales a sus coches. Los fines ya no están fuera de la técnica, sino en ella misma; al hacerlo, determinan el transcurso ulterior de los procesos. La técnica, aunque aparentemente comience como una actividad que tiene su fin fuera de sí misma, termina por englobar sus propios fines, lo que la convierte en un fin. La técnica, lejos de ser una actividad sin fin (atelés), llega a hacerse ella misma un fin. El surgir técnico, precisamente porque incluye un regir, puede llegar a "erigirse" a sí mismo como su propio fin. Observemos ahora algo más: precisamente porque la técnica se convierte a sí misma en fin, se constituye como un proceso sin final. Parafraseando a Aristóteles, pero transformando al mismo tiempo su concepto de la producción, podemos decir que producimos y hemos producido, y, por lo tanto, continuamos indefinidamente produciendo. $\mathrm{Al}$ apropiarse de los fines, la técnica 
carece de final, se hace interminable. Por eso mismo, el sentido de la técnica ya no está fuera de sí misma, en objetivos decididos por el ser humano, sino en su propio interior: producir por producir, crecer por crecer.

El pensamiento moderno tendería a pensar que esos procesos técnicos pueden ser fácilmente controlados por un sujeto humano conciente, situado más allá de sus actos. Pero las cosas no son tan sencillas, no solo por el hecho ya mencionado de que la persona no está por detrás del surgir, sino por una razón que incumbe a la esencia misma de la técnica como un surgir dirigido. Y es que en este nos encontramos con dos "regimientos" que no son conmensurables ni pueden aspirar a ponerse en una relación biunívoca: por un lado, tenemos el regir que caracteriza el surgir de todas las cosas, incluyendo los productos técnicos; por otro lado, tenemos el regir de quienes pretenden dirigir el acontecer mismo del surgir. No es el regir de las cosas, sino que el del humano que trata de orientar el surgir mismo de las cosas. Pero son dos regires inconmensurables. El primero corresponde a la alteridad radical de todo lo que surge. El segundo no es otro que el de las intenciones del logos humano, tratando de orientar el surgir mismo de las cosas. Así como en el teorema de Gödel un sistema axiomático plantea problemas que pueden no ser solubles con el sistema finito de axiomas y postulados con los que se ha construido, mucho más radicalmente todo surgir desborda, por la alteridad radical de lo que surge, toda pretensión de abarcarlo en una orientación determinada. Por eso mismo, la técnica como surgir dirigido nunca puede ser plenamente poseída por la dirección humana. El surgir dirigido, por su propia índole constitutiva, siempre estará también “dis-regido”. La dirección será siempre una "dis-rección" de la que continuamente surgirán efectos no intencionalmente planeados. El proyecto de una técnica plenamente apropiada por un sujeto conciente es una ilusión más de la modernidad, que no resiste un análisis praxeológico de la índole radical de lo técnico.

Sin embargo, la solución no puede ser volver a una situación premoderna, como las añoradas por Tolkien. Tiene razón Heidegger cuando cita a Hölderlin para recordar que la salvación está donde acecha el peligro. Pero la salvación no consiste simplemente en una vuelta mística sobre el acontecer del surgir. Más bien hay que preguntarse qué es lo que permite que los fines de la técnica como surgir dirigido se anclen en la técnica misma, sin que nada la trascienda. La salvación completa de la técnica solamente es posible como una sanación radical de la praxis humana, que la libere de su fatal pretensión de justificarse a sí misma por sus resultados. En el relato 
bíblico, la historia de Babel no es más que la culminación de la pretensión adámica de vivir de los frutos de las propias actuaciones, algo que aboca al ser humano a perder su vida como consecuencia de estar desgastando la tierra para obligarla a producir unos escasos frutos. Sin embargo, no es tema de la filosofía la salvación. Lo que la filosofía solamente puede comentar acerca de cualquier pretensión de salvación es que no hay praxis humana en el mundo sin dirección del surgir, sin técnica. Una praxis salvada en el mundo sería también una praxis técnica. Cualquier corrección de la técnica solamente es pensable como una nueva dirección del surgir y, por tanto, como una técnica.

La corrección de la técnica no es nada ajeno a la técnica misma. El "corregir" no es sino una forma concreta del dirigir, de ese dirigir que pertenece esencialmente a la técnica misma. Por eso, cualquier corrección de la técnica no puede hacer al margen de la técnica misma. En el corregir de la técnica, es esencial el "co-". El corregir es un regir compartido, un regir democratizado. No hay razón alguna para pensar que la democracia sea algo que concierne solamente a la política y no a la producción técnica que ocupa una gran parte de nuestras vidas. Sin embargo, conviene hacer algunas matizaciones respecto a cualquier idea vulgar ("demótica") de la democracia. En primer lugar, el corregir que aspira a dirigir la técnica, por ser intrínseco a la técnica misma, no puede hacerse sin el dirigir de los técnicos. En segundo lugar, el corregir que aspira a dirigir la técnica incluye necesariamente una consideración de la perspectiva de las generaciones futuras, afectadas también por el dirigir del presente y su inevitable "dis-regir". En tercer lugar, el corregir viable no encaja en el mito del subjetivismo moderno de un género humano constituido en dueño y señor de su propia actividad. El corregir es una variante del dirigir que incluye el reconocimiento de la apertura del surgir, pues sabe de la inconmensurabilidad de los regires, y de la imposibilidad de que nuestras intenciones agoten la alteridad radical de lo que surge. El "co-" del corregir incluye y respeta el dinamismo del surgir.

En su famoso prólogo a la segunda edición de la Crítica de la razón pura, Kant mencionaba dos actitudes posibles ante la naturaleza: la del discípulo que escucha todo lo que el maestro quiere y la del juez que obliga a los testigos a responder a las preguntas que él les formula. Caben, sin embargo, otras actitudes ante el surgir. Este, entendido como regir de las cosas en alteridad radical, no se limita al brotar de lo natural, sino que incluye todo el orbe de los productos de la técnica. Y la naturaleza, como modo del surgir, no es solo un sistema de leyes que pueda corresponderse biunívocamente 
con las estructuras de nuestro entendimiento. Hay una irreductible alteridad radical de lo que surge que impone su respeto ante toda pretensión de dirigir y de corregir. Ante el surgir no tenemos que ser discípulos premodernos que se limitan a escuchar reverentemente a la physis. Pero tampoco tenemos que ser jueces modernos que creen que el elenco de sus preguntas posibles agota el ámbito de todas las respuestas. Ante el surgir, podemos ser discípulos que se atreven a preguntar y maestros que se atreven a escuchar. Este atrevimiento no es otra cosa que verdadero respeto, y este respeto no es ante algo ajeno, sino acerca de nosotros mismos. Y es que el surgir no es algo más que la esencia misma de todos nuestros actos, los cuales configuran nuestro propio carácter personal. La técnica es algo esencialmente humano, y la corrección de su "dis-regir" no es más que una forma mejorada de ser nosotros mismos.

\section{Referencias}

Aristóteles. (1998 [Met]). Metafísica (Tomás Calvo Martínez, trad.). Madrid: Editorial Gredos.

Husserl, E. (1973). Die idee der Phenomenologie. Funf Vorlesungen: La Haya.

San Martin, J. (1973). La fenomenología de Husserl como utopía de la razón. Barcelona: Anthropos.

Zubiri, X. (1984). Inteligencia sentiente. Inteligencia y realidad. Madrid: Tercer Mundo. 